\title{
miR-155 inhibitor reduces the proliferation and migration in osteosarcoma MG-63 cells
}

\author{
HUICHENG LV ${ }^{1,2}$, JUN GUO ${ }^{2},{\text { SIQIN } \mathrm{LI}^{3} \text { and DIANMIN JIANG }}^{1}$ \\ ${ }^{1}$ Department of Orthopaedics, The First Affiliated Hospital of Chongqing Medical University, Chongqing 404000; \\ ${ }^{2}$ Department of Orthopaedics, The Second Affiliated Hospital of Inner Mongolia Medical University, Hohhot, Inner Mongolia \\ 010030; ${ }^{3}$ Department of Ultrasound, The People's Hospital of Inner Mongolia, Hohhot, Inner Mongolia 010010, P.R. China
}

Received February 28, 2014; Accepted August 15, 2014

DOI: $10.3892 /$ etm.2014.1942

\begin{abstract}
As the most common malignant primary bone tumor in childhood, osteosarcoma (OS) maintains a high recurrence, despite the significant improvements in the overall survival rate of high-grade OS patients during the recent decades. Therefore, a novel therapy strategy is required for OS treatment. Recently, various microRNAs (miRNAs or miRs) have been confirmed as deregulated in OS, and the miR-155 dysregulation in OS has been discovered by the microarray analysis. In the present study, the regulation of $m i R-155$ on the OS cell proliferation, migration and invasion on the MG-63 cells was explored in vitro. The $m i R-155$ mimics were found to promote cell proliferation, colony formation, migration and invasion significantly, compared to the control miRNA. An $m i R-155$ inhibitor was also used to evaluate whether $m i R-155$ served as a therapeutic target for OS. The results demonstrated that the miR-155 inhibitor significantly reduced the proliferation, colony formation, migration and invasion of the MG-63 OS cells. Thus, the study confirmed the oncogenic regulation on the OS progression of miR-155, which could serve as a therapeutic target with an $m i R-155$ inhibitor.
\end{abstract}

\section{Introduction}

Osteosarcoma (OS) accounts for $\sim 2.5 \%$ of all malignancies in pediatric patients and $\sim 20 \%$ of all primary bone cancers (1), with a morphological and malignant heterogeneity (2). The majority of OS variant cells are extremely aggressive, with a capability of rapid growth and early metastasis. Currently, $>30 \%$ of OS patients with localized disease eventually develop distant metastases, mostly to the lungs and bones (3),

Correspondence to: Dr Dianming Jiang, Department of Orthopaedics, The First Affiliated Hospital of Chongqing Medical University Yuanjiagang, 1 Friendship Road, Yuzhong, Chongqing 400016, P.R. China

E-mail: dianm_jiang@163.com

Key words: miR-155 inhibitor, osteosarcoma, proliferation, migration even following chemotherapy and surgical treatment. The outcome of OS patients has not significantly improved over the last 20 years, and there has been no significant advance in OS treatment, as the molecular mechanism underlying the highly efficient proliferation and migration of OS cells remains largely unknown. Thus, there is an urgency to identify the details regarding tumor progression and to develop novel therapy strategies for this disease.

microRNAs (miRNAs or miRs) are endogenous non-coding RNAs with 18-24 nucleotides, which regulate gene expression (4) by binding the target mRNA's 3' untranslated region (5), in a wide range of organisms, and in a broad array of cell processes in mammals (5-7). It is well known that cancer is driven by the deregulation of a complexity of oncogenic and tumor suppressive genes, and emerging evidence shows that miRNAs are deregulated in various types of cancer (8-10), and play oncogenic and tumor suppressive roles, contributing to tumor formation and development (11-13). Recently, various miRNAs have been confirmed to be deregulated in OS $(14,15)$. The oncogenic miRNA, $m i R-21$, which is aberrantly overexpressed in numerous types of tumor and induces cancer cell growth, migration, invasion and metastasis $(16,17)$, has also been indicated to be significantly overexpressed in OS tissues and induces invasion and migration of the OS cell line, MG-63, by negatively regulating the tumor suppressor gene, reversion-inducing-cysteine-rich protein with kazal motifs (18). The oncogenic miR-93 also induces proliferation and invasion in OS (19), whereas $m i R-20 a$ promotes OS metastasis by regulating Fas expression (20). By contrast, the tumor suppressive miRNAs, including miR-199a-3p (21), $m i R-125 b$ (22), $m i R-143$ (23), $m i R-382$ and $m i R-134$ (24), are significantly downregulated in OS cells and attenuate proliferation and inhibition of migration, reduce cell viability and induce apoptosis. $m i R-155$ is well identified as an oncogenic miRNA in leukemia $(25,26)$ and breast cancer $(14)$, contributing to tumorigenicity and progression.

Neoadjuvant chemotherapy has improved the cure rate of OS patients $(27,28)$. However, patients that are not sensitive to these drugs have a poor prognosis. In addition, the frequent acquisition of drug-resistance is often associated with chemotherapy and is a significant obstacle to achieving favorable outcomes. Thus, exploring novel targets for therapy and developing more effective treatment strategies for this disease is 
required. Recently, Lauvrak et al (29) identified that miR-155 overexpression in OS cell lines was associated with aggressive cancer phenotypes. In the present study, the aim was to evaluate whether $m i R-155$ is a sensitive target for therapy. The regulatory role of $m i R-155$ was determined in the proliferation, invasion and migration of OS cells. Subsequently, the miR-155 inhibitor was evaluated for its inhibition on the OS cell proliferation and migration. The results demonstrated that the miR-155 mimic significantly increased, whereas the $m i R-155$ inhibitor significantly reduced the proliferation and migration of OS MG-63 cells. Therefore, the study revealed miR-155 as a possible therapeutic target for OS.

\section{Materials and methods}

Reagents and cell culture. The human OS cell line, MG-63, was obtained from the Cell Resource Center of the Chinese Academy of Medical Sciences (Beijing, China). MG-63 cells were cultured in Eagle's Minimum Essential Medium (EMEM) (Invitrogen, Carlsbad, CA, USA), supplemented with $2 \mathrm{mM}$ glutamine, $1 \%$ non-essential amino acids and $10 \%$ fetal bovine serum (FBS) (Invitrogen). The cells were incubated at $37^{\circ} \mathrm{C}$ with $5 \% \mathrm{CO}_{2}$. The miR-155 mimic (Qiagen, Valencia, CA, USA) or inhibitor (Qiagen) was used to elevate or reduce the $m i R$-155 level via lipofectamine 2000 (Invitrogen). miR-Con was used as a control.

$R N A$ extraction and reverse transcription quantitative polymerase chain reaction ( $R T-q P C R)$ miR-155 assay. The mirVana miRNA Isolation kit (Ambion, Austin, TX, USA) was used to extract miRNAs from the MG-63 cells, and the mirVana RT-qPCR miRNA Detection kit (Ambion) was used to quantify the $m i R-155$ expression, with the U6 small nuclear RNA as the internal control. $\Delta \Delta \mathrm{Ct}$ method was used for relative quantification (30). The RT-qPCR was performed using SYBR Green with the LightCycle 2.0 (Roche Diagnostics GmbH, Mannheim, Germany).

Cell viability assay and cell colony formation assay. The MTT assay was adopted to determine the cell viability. MG-63 cells were seeded in 96-well plates and transfected with the miR-155 mimic, inhibitor or control, with $\sim 85 \%$ confluence. The cells were washed with warm PBS 6 h post-tranfection and were replaced with RPMI-1640 medium containing $1 \%$ FBS, and were cultured for various time. Subsequently, the MTT assay was conducted. Briefly, the incubation medium in the cell wells was replaced with $50 \mu 11 \mathrm{x}$ MTT solution, and the cells were incubated for $2 \mathrm{~h}$ at $37^{\circ} \mathrm{C}$. Post-incubation, the MTT solution was discarded and $150 \mu 1$ DMSO was added to dissolve the precipitate completely at room temperature. The optical density was measured at $570 \mathrm{~nm}$ using a spectrophotometer, the cell viability was expressed as relative viable cells (\%) to the control MG-63 cells. For the cell colony formation assay, $2 \times 10^{3}$ cells were incubated in 6 -well plates at $37^{\circ} \mathrm{C}$ containing $5 \% \mathrm{CO}_{2}$. Ten days post-incubation, the cells were stained with crystal violet $(0.005 \%)$ for $30 \mathrm{~min}$ and the colony numbers were recorded by Image J software (National Institutes of Health, Bethesda, MD, USA). For the proliferation assay, post-transfection with the miR-155 mimic, inhibitor or control, cells were incubated in cell counting kit 8 (CCK-8;
Dojindo Laboratories, Kumamoto, Japan) for various times. The $450 \mathrm{~nm}$ absorbance of each well was detected following visual color occurrence.

Cell migration and invasion assay. The cell migration was determined by the scratch assay. The cells were cultivated to $90 \%$ confluence on 12-well plates and were transfected with the miR-155 mimic, inhibitor or control. Subsequently, Cell Scrapers (Corning Inc., Corning, NY, USA) were utilized to scratch the confluent cells $24 \mathrm{~h}$ post-transfection. The procedures of cellular growth were observed at 0 and $96 \mathrm{~h}$. All the experiments were repeated in triplicate. The Transwell migration chambers were used to evaluate the MG-63 cell invasion. The cells were first seeded at a density of $1 \times 10^{5}$ cells in serum-free media on the upper chamber with the non-coated membrane ( $8 \mu \mathrm{m}$ pore size; Millipore, Zug, Switzerland). The lower chamber contained EMEM with $20 \% \mathrm{FBS}$ as a chemoattractant. The cells in the upper chamber were discarded using cotton wool after $24 \mathrm{~h}$ and the migration cells in the lower chamber were counted using a microscope (Olympus, Tokyo, Japan). All the experiments were repeated in triplicate.

Statistical analysis. The results are expressed as mean \pm standard error. Student's t-test was performed to compare the differences between two groups. Statistical analysis was conducted by SPSS 17.0 software (SPSS, Inc., Chicago, IL, USA). $\mathrm{P}<0.05$ was considered to indicate a statistically significant difference; and in particular, the results are shown as no significance, ${ }^{*} \mathrm{P}<0.05,{ }^{* *} \mathrm{P}<0.01$ or ${ }^{* * *} \mathrm{P}<0.001$.

\section{Results}

miR-155 inhibitor reduces the viability and proliferation of MG-63 cells. To confirm the promotion of miR-155 to the OS cell proliferation, the miR-155 expression level was manipulated in MG- 63 cells, via transfection with the miR-155 mimic or inhibitor. The miR-155 in mimic-transfected cells was significantly higher than that of the control cells $(\mathrm{P}<0.001)$ $48 \mathrm{~h}$ post transfection, whereas the miR-155 level in the $m i R$-155 inhibitor-transfected cells was significantly lower than in the control cells $(\mathrm{P}<0.05)($ Fig. 1A). Subsequently, the influence of the miR-155 mimic, inhibitor or control on the cell viability was examined. The MTT assay results (Fig. 1B) demonstrated that the viability of the MG-63 cells $48 \mathrm{~h}$ post-transfection decreased significantly following the transfection of the miR-155 inhibitor compared to the transfection of miR-Con $(\mathrm{P}<0.05)$; whereas the transfection of the miR-155 mimic ameliorated the viability reduction of MG-63 cells $(\mathrm{P}<0.05)$. Finally, the proliferation of MG-63 cells was determined post-transfection for $24 \mathrm{~h}$ with the miR-155 mimic, inhibitor or control in a 25 or $50 \mathrm{nM}$ concentration by the CCK-8 assay. Fig. 1C shows that in either concentration, the $m i R-155$ mimic group exhibited a higher proliferation than $m i R-155$ control, whereas the miR-155 inhibitor group reduced proliferation $(\mathrm{P}<0.05)$. In addition, the time-dependent promoting or reducing effect in cell proliferation of the $m i R-155$ mimic or inhibitor was indicated under the condition of enhanced or reduced miR-155 levels in the MG-63 cells $(\mathrm{P}<0.05)$ (Fig. 1D). 
A

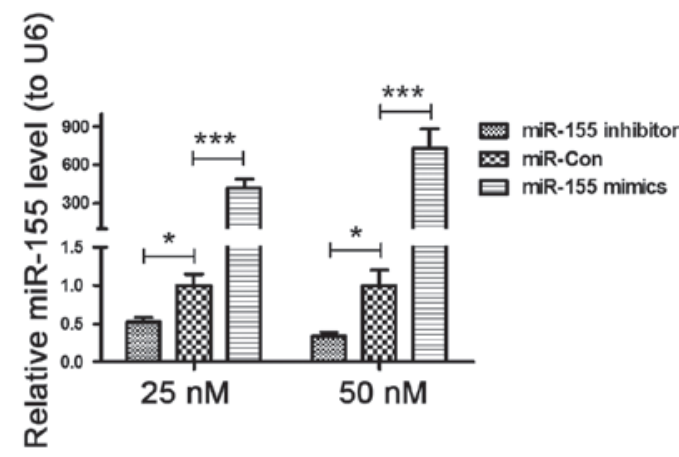

C

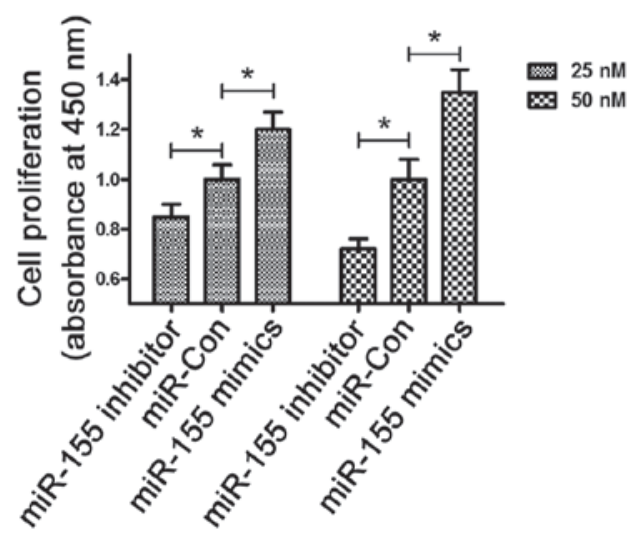

B

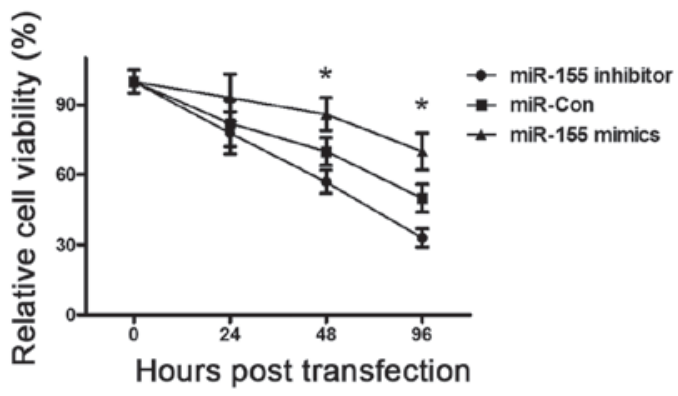

D

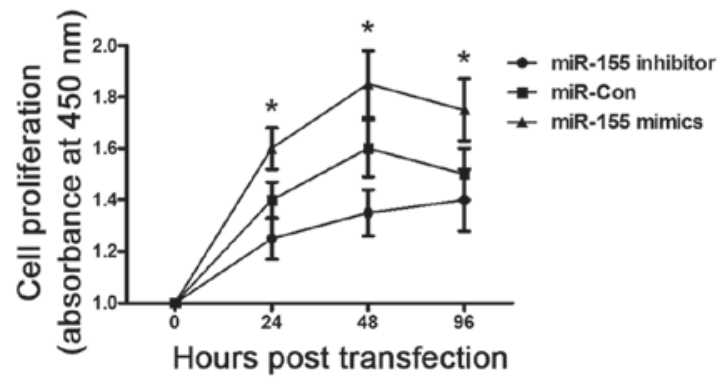

Figure 1. miRNA-155 inhibitor reduces the cellular viability and proliferation of MG-63 cells in vitro. (A) The miR-155 level in MG-63 cells was compared among the miR-155 mimic, inhibitor and control transfection groups. (B) Viability of MG-63 cells was determined with the MTT assay post-transfection of the $m i R-155$ mimic, inhibitor and control. (C) Cellular proliferation of MG-63 cells post-miR-155 mimic, inhibitor or control transfection at $25 \mathrm{nM}$ or $50 \mathrm{nM}$ by the CCK-8 assay. (D) Growth curve of cell proliferation was made following treatment with the miR-155 mimic, inhibitor or control in MG-63 cells by the CCK-8 assay. All the experiments were performed separately in triplicate. ${ }^{*} \mathrm{P}<0.05,{ }^{* *} \mathrm{P}<0.01$ and ${ }^{* * * *} \mathrm{P}<0.001$. CCK-8, cell counting kit 8 .

A

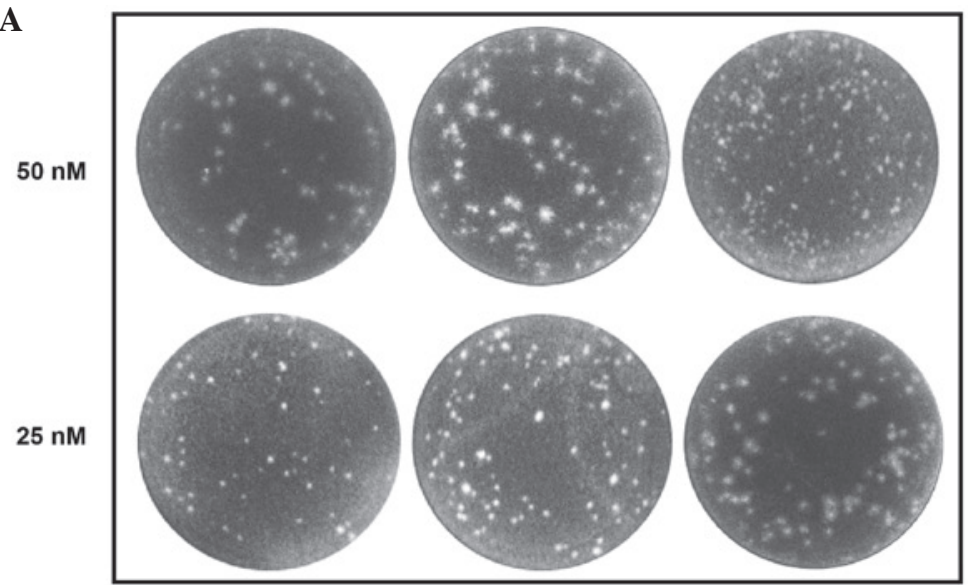

B

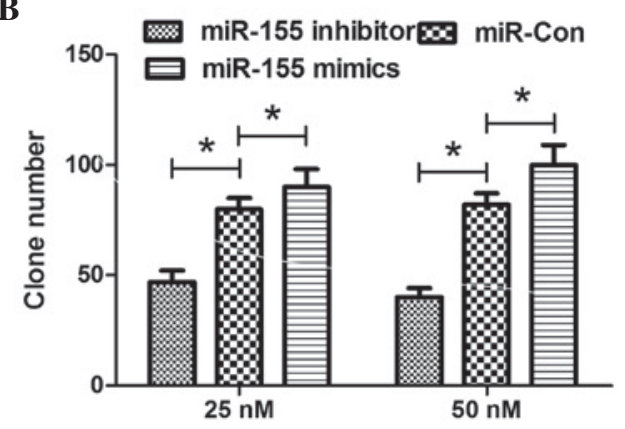

Figure 2. miRNA-155 inhibitor reduces the colony formation of MG-63 cells. (A) MG-63 cells were transfected with the miR-155 mimic, inhibitor or control at $25 \mathrm{nM}$ or $50 \mathrm{nM}$, and were detected for colony formation. (B) The morphological characteristics of MG-63 colony formation and the number of colony formation was calculated as comparison. All the results were from experiments performed separately in triplicate. ${ }^{\text {P }}<0.05$.

miR-155 inhibitor reduces clone formation of $M G-63$ cells. The difference in colony formation was also detected for the MG-63 cells transfected with the miR-155 mimic, inhibitor or control in the 25 or $50 \mathrm{nM}$ concentration. The image of the colonies is shown in Fig. 2A, and the MG-63 cells that were transfected with the $m i R-155$ mimic in a 25 or $50 \mathrm{nM}$ concentration formed more colonies than the $m i R$-control-transfected cells, whereas the miR-155 inhibitor reduced the colony formation of $\mathrm{MG}-63$ cells $(\mathrm{P}<0.05)$
(Fig. 2B). All these findings indicate that the miR-155 inhibitor reduced the clonegenesis of MG-63 cells, while the upregulated $m i R-155$ in the cells had a significant role in enhancing the proliferative capability and colony formation of the MG-63 cells.

miR-155 inhibitor reduces the migration and invasion of $M G-63$ cells. Cell migration is known to contribute to tumor metastasis (31). The migration of the MG-63 cells was determined 
A
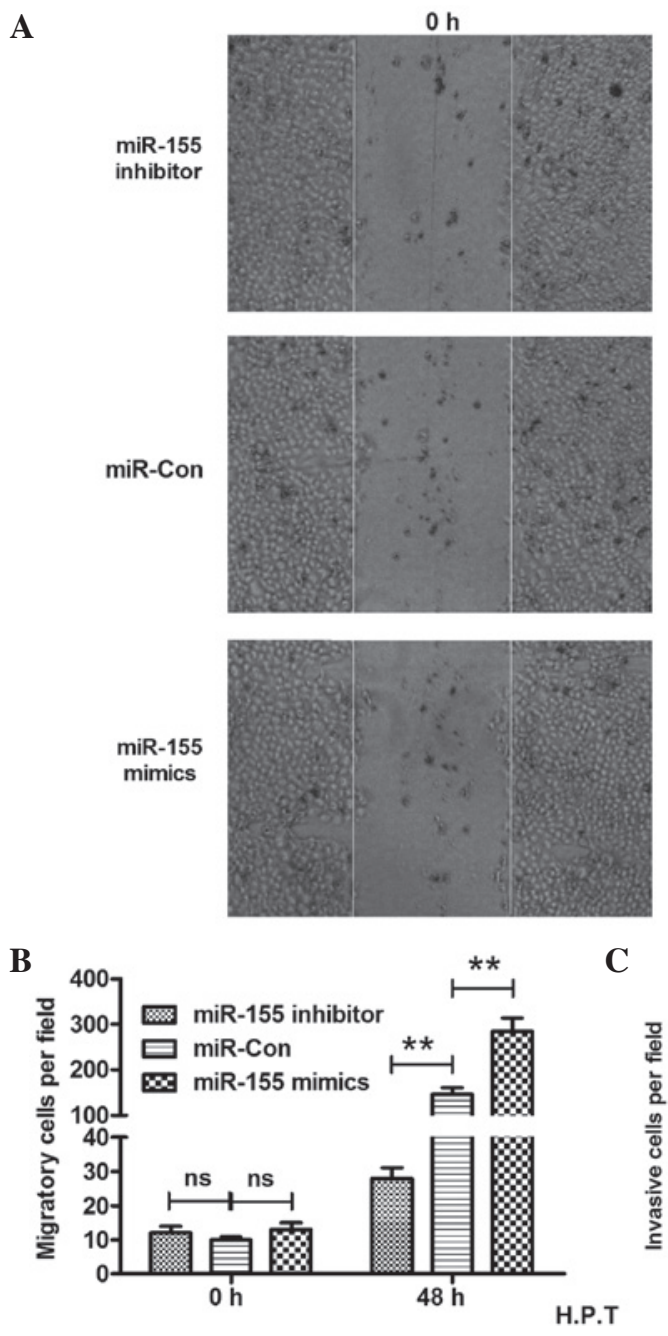
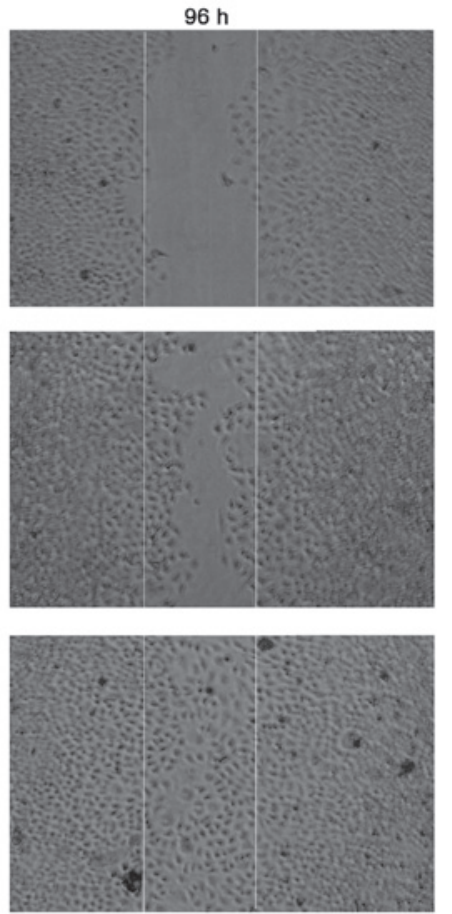

C

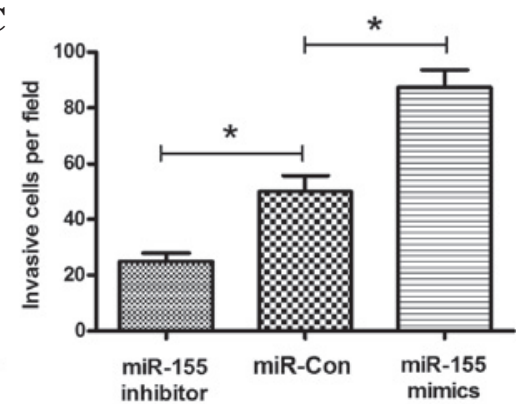

Figure 3. miRNA-155 inhibitor reduces the migration and invasion of MG-63 cells. (A) Post-transfection with miR-155 mimic, inhibitor or control, the MG-63 cells were shown at 0 or $96 \mathrm{~h}$ by the scratch assay. Solid lines are shown as a baseline. (B) The migratory cells were counted respectively in the $m i R-155$ mimic, inhibitor or control groups. (C) The number of tumor cell invasion was calculated to compare the miR-155 mimic, inhibitor or control groups by the Transwell invasion assays. Experiments were performed separately in triplicate. ns, no significance, ${ }^{*} \mathrm{P}<0.05 ;{ }^{* *} \mathrm{P}<0.01$.

post-transfection of the $m i R-155$ mimic, inhibitor or control by the scratch assay. The results shown in Fig. 3A indicate that more inoculation occurred $96 \mathrm{~h}$ post-scratch. The MG-63 cells post $m i R$-155 mimic-transfection migrated significantly faster than the $m i R$-Con-transfected MG-63 cells, as there were more cells crossing the base line $(\mathrm{P}<0.01)$ (Fig. 3B). In addition, the $m i R-155$ inhibitor reduced the migration of MG-63 cells significantly, as less cells crossed the base line in this group than in the control group $(\mathrm{P}<0.01)$ (Fig. 3B). The miR-155 inhibitor clearly reduced the MG-63 cell migration. The blockage of the miR-155 inhibitor to the cell invasion was also demonstrated. The Transwell invasion chamber assay demonstrated clearly that there was a significant difference in the cell invasion between the miR-155 mimic and control groups, or between the $m i R-155$ inhibitor and control groups. The number of invasive cells was $50 \pm 10$ cells in the control group, whereas the invasive cell number in the miR-155 mimic or inhibitor group was $88 \pm 12$ and $25 \pm 4$ cells, respectively (Fig. $3 \mathrm{C})(\mathrm{P}<0.05$, respectively). All the results indicated that overexpression of miR-155 stimulated the migration and invasion of OS cells, and the miR-155 inhibitor reduced the migration and invasion of the MG-63 cells.

\section{Discussion}

As the most common malignant primary bone tumor in childhood (32), OS maintains a high recurrence of $30-40 \%$, and $80 \%$ of OS patients with metastatic disease at diagnosis will relapse $(27,33,34)$, regardless of the significant improvements in the overall survival rate of high-grade OS patients during the past decades. Failure of standard multimodal therapy for the disease is associated with an extremely poor prognosis, and therefore, novel drugs or combination therapies are required for patients with recurrent or refractory high-grade OS. Several clinical studies have been conducted to evaluate the efficiency of a combined therapy with gemcitabine and docetaxel in recurrent or refractory OS, and the effect of the gemcitabine-docetaxel combination regimen in recurrent or refractory OS patients remains controversial (35-37).

Extensive studies have been conducted to identify the oncogenes that are suitable to become targets of monoclonal antibodies and small inhibitors. Antibodies or inhibitors were used to knockdown the tyrosine kinase receptors, KIT, platelet-derived growth factor receptors and 
vascular endothelial growth factor receptors (38-41), however, their inhibition lacked antitumor activity. The monoclonal antibody anti-insulin-like growth factor receptor-I was also promising preclinically, but was not confirmed to be effective in the clinical setting (42). Recently, several studies have focused on the signal transduction pathways of phosphatidylinositol 3'-kinase/mammalian target of rapamycin (43) and mitogen-activated protein kinases. Their inhibition proved highly effective in OS preclinical models (44).

Previously, various miRNAs have been confirmed to be deregulated in OS $(14,15)$. Several oncogenic miRNAs, including $m i R-21$, $m i R-93$ and $m i R-29$, have been indicated to be overexpressed and to induce cancer cell growth, migration, invasion and metastasis (16-19,45). Recently, the miR-155 dysregulation in OS was discovered by microarray analysis (29). In the present study, the regulation of $m i R-155$ was explored on the OS cell proliferation, migration and invasion on the MG-63 cell in vitro. The $m i R-155$ mimic was shown to promote the cell proliferation, colony formation, migration and invasion significantly, compared to the control miRNA. An miR-155 inhibitor was also used to evaluate whether $m i R-155$ could serve as a therapeutic target for OS. The results demonstrated that the miR-155 inhibitor significantly reduced the proliferation, colony formation, migration and invasion of MG-63 OS cells.

In conclusion, the present study confirmed that the oncogenic regulation on the OS progression of $m i R-155$ could serve as a therapeutic target with an $m i R-155$ inhibitor.

\section{References}

1. Ottaviani $\mathrm{G}$ and Jaffe N: The epidemiology of osteosarcoma Cancer treatment and research 152: 3-13, 2009.

2. Dorfman HD and Czerniak B: Bone cancers. Cancer 75: 203-210, 1995.

3. Meyers PA, Heller G, Healey J, et al: Chemotherapy for nonmetastatic osteogenic sarcoma: the Memorial Sloan-Kettering experience. J Clin Oncol 10: 5-15, 1992.

4. Ambros V: MicroRNA pathways in flies and worms: growth, death, fat, stress, and timing. Cell 113: 673-676, 2003.

5. Bartel DP: MicroRNAs: target recognition and regulatory functions. Cell 136: 215-233, 2009.

6. Brennecke J, Hipfner DR, Stark A, Russell RB and Cohen SM: bantam encodes a developmentally regulated microRNA that controls cell proliferation and regulates the proapoptotic gene hid in Drosophila. Cell 113: 25-36, 2003.

7. Reinhart BJ, Slack FJ, Basson M, et al: The 21-nucleotide let-7 RNA regulates developmental timing in Caenorhabditis elegans. Nature 403: 901-906, 2000.

8. Esquela-Kerscher A and Slack FJ: Oncomirs-microRNAs with a role in cancer. Nature Revs Cancer 6: 259-269, 2006.

9. Wang D, Qiu C, Zhang H, Wang J, Cui Q and Yin Y: Human microRNA oncogenes and tumor suppressors show significantly different biological patterns: from functions to targets. PLoS One 5: e13067, 2010.

10. Zhang B, Pan X, Cobb GP and Anderson TA: microRNAs as oncogenes and tumor suppressors. Dev Biol 302: 1-12, 2007.

11. Chen CZ: MicroRNAs as oncogenes and tumor suppressors. N Engl J Med 353: 1768-1771, 2005.

12. Ventura A and Jacks T: MicroRNAs and cancer: short RNAs go a long way. Cell 136: 586-591, 2009.

13. Spizzo R, Nicoloso MS, Croce CM and Calin GA: SnapShot: MicroRNAs in Cancer. Cell 137: 586-586 e581, 2009.

14. Zhou G, Shi X, Zhang J, Wu S and Zhao J: MicroRNAs in osteosarcoma: from biological players to clinical contributors, a review. J Int Med Res 41: 1-12, 2013.

15. Li Y, Zhang J, Zhang L, Si M, Yin H and Li J: Diallyl trisulfide inhibits proliferation, invasion and angiogenesis of osteosarcoma cells by switching on suppressor microRNAs and inactivating of Notch-1 signaling. Carcinogenesis 34: $1601-1610,2013$
16. Asangani IA, Rasheed SA, Nikolova DA, et al: MicroRNA-21 (miR-21) post-transcriptionally downregulates tumor suppressor Pdcd4 and stimulates invasion, intravasation and metastasis in colorectal cancer. Oncogene 27: 2128-2136, 2008.

17. Meng F, Henson R, Wehbe-Janek H, Ghoshal K, Jacob ST and Patel T: MicroRNA-21 regulates expression of the PTEN tumor suppressor gene in human hepatocellular cancer. Gastroenterology 133: 647-658, 2007.

18. Ziyan W, Shuhua Y, Xiufang W and Xiaoyun L: MicroRNA-21 is involved in osteosarcoma cell invasion and migration. Med Oncol 28: 1469-1474, 2011.

19. Montanini L, Lasagna L, Barili V, et al: MicroRNA cloning and sequencing in osteosarcoma cell lines: differential role of miR-93. Cell Oncol (Dordr) 35: 29-41, 2012.

20. Huang G, Nishimoto K, Zhou Z, Hughes D and Kleinerman ES: miR-20a encoded by the miR-17-92 cluster increases the metastatic potential of osteosarcoma cells by regulating Fas expression. Cancer Res 72: 908-916, 2012.

21. Duan Z, Choy E, Harmon D, et al: MicroRNA-199a-3p is downregulated in human osteosarcoma and regulates cell proliferation and migration. Mol Cancer Ther 10: 1337-1345, 2011.

22. Liu LH, Li H, Li JP, et al: miR-125b suppresses the proliferation and migration of osteosarcoma cells through down-regulation of STAT3. Biochem Biophys Res Commun 416: 31-38, 2011.

23. Zhang $\mathrm{H}$, Cai $\mathrm{X}$, Wang $\mathrm{Y}$, Tang $\mathrm{H}$, Tong $\mathrm{D}$ and Ji F: microRNA-143, down-regulated in osteosarcoma, promotes apoptosis and suppresses tumorigenicity by targeting Bcl-2. Oncol Rep 24: 1363-1369, 2010.

24. Thayanithy V, Sarver AL, Kartha RV, et al: Perturbation of $14 \mathrm{q} 32$ miRNAs-cMYC gene network in osteosarcoma. Bone 50: 171-181, 2012

25. Eis PS, Tam W, Sun L, et al: Accumulation of miR-155 and BIC RNA in human B cell lymphomas. Proc Natl Acad Sci USA 102: 3627-3632, 2005.

26. Kluiver J, Poppema S, de Jong D, et al: BIC and miR-155 are highly expressed in Hodgkin, primary mediastinal and diffuse large B cell lymphomas. J Pathol 207: 243-249, 2005.

27. Provisor AJ, Ettinger LJ, Nachman JB, et al: Treatment of nonmetastatic osteosarcoma of the extremity with preoperative and postoperative chemotherapy: a report from the Children's Cancer Group. J Clin Oncol 15: 76-84, 1997.

28. Goorin AM, Schwartzentruber DJ, Devidas M, et al; Pediatric Oncology Group: Presurgical chemotherapy compared with immediate surgery and adjuvant chemotherapy for nonmetastatic osteosarcoma: Pediatric Oncology Group Study POG-8651. J Clin Oncol 21: 1574-1580, 2003.

29. Lauvrak SU, Munthe E, Kresse SH, et al: Functional characterisation of osteosarcoma cell lines and identification of mRNAs and miRNAs associated with aggressive cancer phenotypes. Br J Cancer 109: 2228-2236, 2013.

30. Livak KJ and Schmittgen TD: Analysis of relative gene expression data using real-time quantitative PCR and the 2(-Delta Delta C(T)) Method. Methods 25: 402-408, 2001.

31. Parkin DM, Bray F, Ferlay J and Pisani P: Global cancer statistics, 2002. CA Cancer J Clin 55: 74-108, 2005.

32. Nagarajan R, Weigel BJ, Thompson RC and Perentesis JP: Osteosarcoma in the first decade of life. Med Pediatr Oncol 41: 480-483, 2003

33. Bramwell VH, Burgers M, Sneath R, et al: A comparison of two short intensive adjuvant chemotherapy regimens in operable osteosarcoma of limbs in children and young adults: the first study of the European Osteosarcoma Intergroup. J Clin Oncol 10: 1579-1591, 1992

34. Bacci G, Picci P, Ferrari S, et al: Primary chemotherapy and delayed surgery for nonmetastatic osteosarcoma of the extremities. Results in 164 patients preoperatively treated with high doses of methotrexate followed by cisplatin and doxorubicin. Cancer 72: 3227-3238, 1993.

35. Mora J, Cruz CO, Parareda A and de Torres C: Treatment of relapsed/refractory pediatric sarcomas with gemcitabine and docetaxel. J Pediatr Hematol Oncol 31: 723-729, 2009.

36. McTiernan A and Whelan JS: A Phase II Study of Docetaxel for the Treatment of Recurrent Osteosarcoma. Sarcoma 8: 71-76, 2004.

37. Navid F, Willert JR, McCarville MB, et al: Combination of gemcitabine and docetaxel in the treatment of children and young adults with refractory bone sarcoma. Cancer 113: 419-425, 2008. 
38. McGary EC, Weber K, Mills L, et al: Inhibition of platelet-derived growth factor-mediated proliferation of osteosarcoma cells by the novel tyrosine kinase inhibitor STI571. Clin Cancer Res 8: 3584-3591, 2002.

39. Sulzbacher I, Birner P, Trieb K, Traxler M, Lang S and Chott A: Expression of platelet-derived growth factor-AA is associated with tumor progression in osteosarcoma. Mod Pathol 16: 66-71, 2003.

40. Kubo T, Piperdi S, Rosenblum J, et al: Platelet-derived growth factor receptor as a prognostic marker and a therapeutic target for imatinib mesylate therapy in osteosarcoma. Cancer 112: 2119-2129, 2008

41. Kaya M, Wada T, Akatsuka T, et al: Vascular endothelial growth factor expression in untreated osteosarcoma is predictive of pulmonary metastasis and poor prognosis. Clin Cancer Res 6: $572-577,2000$
42. Kolb EA, Kamara D, Zhang W, et al: R1507, a fully human monoclonal antibody targeting IGF-1R, is effective alone and in combination with rapamycin in inhibiting growth of osteosarcoma xenografts. Pediatr Blood Cancer 55: 67-75, 2010.

43. Manara MC, Nicoletti G, Zambelli D, et al: NVP-BEZ235 as a new therapeutic option for sarcomas. Clin Cancer Res 16: 530-540, 2010.

44. Pignochino Y, Grignani G, Cavalloni G, et al: Sorafenib blocks tumour growth, angiogenesis and metastatic potential in preclinical models of osteosarcoma through a mechanism potentially involving the inhibition of ERK1/2, MCL-1 and ezrin pathways. Mol Cancer 8: 118, 2009.

45. Zhang W, Qian JX, Yi HL, et al: The microRNA-29 plays a central role in osteosarcoma pathogenesis and progression. Mol Biol (Mosk) 46: 622-627, 2012. 